\title{
Actividad de la colinesterasa total en pobladores que utilizan plaguicidas en La Brea, Lepaterique durante el año 2015
}

\author{
Alba Ruth Blanco, Henry Daniel Ponce, Nahúm Alcides Lanza, \\ Heydi Joseline Velásquez, Gina Lucila Calderón ${ }^{1}$
}

\section{RESUMEN}

Se establecieron los niveles de actividad de la enzima colinesterasa en sangre total de los pobladores de la aldea La Brea, Lepaterique, empleando el método potenciométrico de Michel. Previo a la adquisición de las muestras de sangre se aplicó un instrumento de recolección para conocer las prácticas y cuidados en el manejo de plaguicidas de parte de la población; asimismo, los hábitos de aplicación, medidas de seguridad y tiempo de estar en contacto con estos productos. Mediante los resultados obtenidos en la determinación de la actividad enzimática en pobladores expuestos y no expuestos, se considera normal un valor mayor o igual a 154 unidades de $\mathrm{pH} / \mathrm{ho}$ ra, empleando la desviación estándar de los resultados obtenidos se lograron determinar estadísticamente los valores de corte para señalar una inhibición en la actividad de la enzima en sangre. Así, se obtuvo como valor de corte para establecer una leve inhibición en 133 unidades de $\mathrm{pH} / \mathrm{hora}$ y finalmente aquellos valores menores a 120 unidades de $\mathrm{pH} /$ hora como inhibición moderada. De los 95 pobladores evaluados, solamente tres de ellos presentaron valores menores dentro del rango de inhibición moderada. Finalmente, se presentaron los resultados a la comunidad, lo mismo que una guía rápida para el uso, manejo y cuidados en la utilización de los plaguicidas.

Palabras claves: colinesterasa, método potenciométrico, plaguicidas.

\footnotetext{
${ }^{1}$ Beneficiarios de una beca básica de la DICYP, profesores e instructores del Departamento de Control Químico, Facultad de Química y Farmacia, UNAH: albablancohn@yahoo.com
} 


\section{ABSTRACT}

The activity levels of the enzyme cholinesterase in whole blood of the population of $\mathrm{La}$ Brea, Lepaterique settled using the Michel potentiometric method. Prior to the acquisition of blood samples, a survey was applied to explore the practices and care in handling pesticides on the part of the population. Habits and application security measures, while being in contact with these products. By the results of the determination of enzyme activity in exposed and unexposed people, it is considered normal greater than or equal to 154 units of $\mathrm{pH} /$ hour value, using the standard deviation of the results achieved statistically determine cutoff values to indicate an inhibition in the activity of the enzyme in blood. Thus it was obtained as cutoff to establish a slight inhibition at 133 units of $\mathrm{pH} /$ hour value, and finally those values less than 120 units of $\mathrm{pH} / \mathrm{hour}$ moderate inhibition. Of the 95 persons evaluated only three of them had lower values within the range of moderate inhibition. Finally, the results were presented to the community, as well as a quick guide for the use, management and care in the use of pesticides.

Keywords: cholinesterase, potentiometric method, pesticides. 


\section{INTRODUCCIÓN}

La utilización de plaguicidas a nivel mundial es una práctica común para preservar los cultivos, lo cual es parte de la independencia y seguridad alimentaria de los países, convirtiéndose en un negocio de grandes cantidades de dinero (Cobb y Reade, 2010). Nuestro país no es la excepción y se hace muy común el uso de estos agentes para erradicar las diferentes plagas que pueden afectar los cultivos. Pese a ello, en Honduras, hasta la fecha, no se encuentran estudios recientes sobre los valores de la actividad de la enzima colinesterasa en personas expuestas a los plaguicidas, así como las no expuestas, que puedan brindar información sobre la exposición a estos agentes por parte de la población. El único trabajo del que se tiene conocimiento es el desarrollado por De Sierra y colaboradores, quienes aplicaron un método colorimétrico para determinar los niveles de colinesterasa sérica en obreros que trabajan con plaguicidas de tipo organofosforados.

Se puede definir a los plaguicidas como una sustancia química de origen natural o sintético u organismo vivo, que se utilizan solas, combinadas o en mezclas, para la protección (combatir o destruir, repeler o mitigar: virus, bacterias, hongos, nematodos, ácaros, moluscos, insectos, plantas no deseadas, roedores y otros) de los cultivos y productos agrícolas (Cotos, Manuel, Horna y William, 2002).

En el presente estudio se logró analizar la actividad de la enzima colinesterasa en sangre total para personas expuestas y no expuestas al uso de plaguicidas en la comunidad de La Brea, en el municipio de Lepaterique, ubicado al oeste del Distrito Central, ya que en esta comunidad existe un elevado uso de estos productos químicos, al producir una gran cantidad de hortalizas que son consumidas por la población de la capital. Además, establecer la relación de estos niveles con el grado de toxicidad de los referidos productos en el primer semestre del año 2015. Asimismo, los resultados alcanzados con el estudio pueden servir como punto de partida para futuros estudios relacionados con la presencia de residuos de plaguicidas en alimentos y en muestras ambientales.

Con la presente investigación se alcanzó elaborar una propuesta en el manejo adecuado de los plaguicidas empleados en la comunidad, para que los pobladores conozcan los cuidados y modo empleo; además de las normas de seguridad al momento de la utilización de los plaguicidas, utilizando para ello diferentes estrategias en la divulgación de la información obtenida en el estudio, finalizando con la presentación de los resultados a los pobladores de la comunidad. 
El estudio además representó una oportunidad para que la Facultad de Química y Farmacia se inserte y adquiera información de alto nivel para dar respuestas concretas a los problemas en el manejo y contaminación a causa de plaguicidas.

Desde el punto de vista analítico, al aplicar el método potenciométrico de Michel, se aseguran los resultados obtenidos, ya que este procedimiento ha sido aplicado en otros estudios efectuados en la región latinoamericana (Carmona Fonseca, 2003), siendo de los más sencillos y de bajo costo, con alta precisión y sensibilidad, sin necesidad de instrumentación analítica costosa, así como la obtención de resultados en corto tiempo (Fong Flores y otros, 2010). Pese a ello, son pocos los laboratorios en nuestro país que ofertan este tipo de ensayo, por lo que la parte experimental se desarrolló en el laboratorio de investigación de la Facultad de Química y Farmacia.

\section{MÉTODO}

\section{Diseño}

El diseño de la investigación fue de tipo no experimental, debido a que no hubo manipulación de las variables de exposición a los compuestos organofosforados o carbamatos en la población de estudio de la aldea La Brea, Lepaterique.

\section{Población y muestra}

Para determinar la población total cuya ocupación principal es el rubro de la agricultura, ganadería y agropecuaria en la aldea de La Brea, se trabajó con los datos del censo estadístico del año 2001 del Instituto Nacional de Estadística (INE), siendo en total 245 personas, entre hombres y mujeres.

La muestra de personas expuestas al uso de plaguicidas se calculó mediante la fórmula de la dirección electrónica de la compañía Creative Research Systems (www.surveysystem.com/sscalc.htm (Sample Size Calculator, 2016), empleando un nivel de confianza del $95 \%$, con un margen de error del $10 \%$, resultando en 69 muestras. En el caso del grupo de personas no expuestas se decidió igual cantidad de individuos. 


\section{Entorno}

El estudio fue desarrollado en la comunidad de La Brea, en el municipio de Lepaterique, lugar donde se producen grandes cantidades de hortalizas, las cuales son comercializadas en el Distrito Central. Asimismo, los análisis de laboratorio se efectuaron en la Facultad de Química y Farmacia en el laboratorio de investigación Elvira Castejón, en donde se encuentra el equipamiento de laboratorio necesario.

\section{Intervenciones}

Para la medición potenciométrica se utilizó un medidor multiparamétrico de la marca Hanna, modelo HI-9829, dotado de un electrodo de pH y compensación de temperatura (ATC), modelo HI-7609829. Para la agitación de las muestras se empleó un agitador mecánico (vortex mixer) de la marca Kool-Lab, modelo KS-VM-1000. Todos los reactivos fueron pesados en una balanza analítica marca OHAUS, modelo Explorer Pro, con una sensibilidad de $110 \mathrm{~g}-\mathrm{d}=0.1 \mathrm{mg}$. Para la aplicación del método analítico se adquirieron reactivos a la compañía Analítica Hondureña (ANALIHSA), incluyendo el barbital sódico (5,5-dietil barbitúrico sal sódica) y saponina de la marca Merck; cloruro de acetilcolina, cloruro de sodio y fosfato monobásico de potasio de la marca Sigma Aldrich, soluciones calibradoras de pH, tampón de fosfato ( $\mathrm{pH} 7$ ), tampón de biftalato $(\mathrm{pH} 4)$ y tampón de borato $(\mathrm{pH} 10)$ de la marca J.T. Baker.

El método analítico empleado fue el método potenciométrico de Michel, el cual mide la actividad enzimática en sangre total, reportando los valores en unidades de $\mathrm{pH} / \mathrm{ho}$ ra. El esquema de trabajo utilizado se presenta en la figura 1. La determinación se realiza midiendo $5 \mathrm{ml}$ de solución de saponina al $0,02 \%(\mathrm{p} / \mathrm{v})$ en un vaso de precipitado de $30 \mathrm{ml}$, para agregar posteriormente $5 \mathrm{ml}$ de la solución tampón pH 8. Inmediatamente se añaden 100 microlitros de la muestra de sangre y $1 \mathrm{ml}$ de la solución de cloruro de acetilcolina al 1,5\% (p/v), para colocar el vaso de precipitado en el agitador mecánico durante 15 segundos y se efectúa la medición potenciométrica de la solución para, finalmente, realizar una segunda medición en un aparato multiparamétrico una hora después. Cada muestra y control se determinan por triplicado. Previo a las mediciones se calibró el medidor potenciométrico con las soluciones estándar de $\mathrm{pH}$ a valores de 4,7 y 10 . 
Figura 1. Procedimiento de trabajo efectuado para la determinación potenciométrica

DETERMINACION DE LA ACTIVIDAD DE LA COLINESTERASA
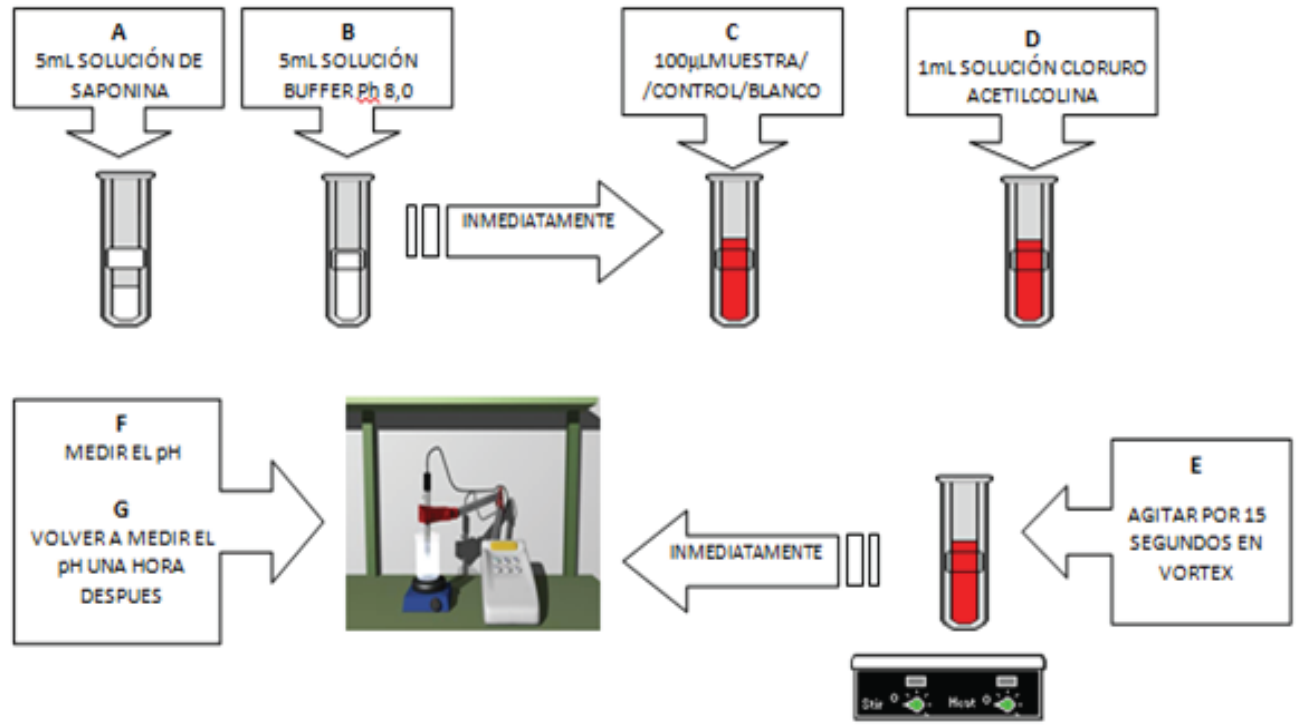

Fuente propia

\section{Análisis estadístico}

Para la evaluación estadística de los datos recolectados se utilizó Microsoft Office, generando hojas de cálculo para los pobladores expuestos y no expuestos. Se calcularon los valores promedios y desviación estándar de los datos.

Ética

Se tomaron las precauciones para asegurar la confidencialidad de los resultados en pobladores que participaron en la investigación. Previamente a la participación de los pobladores expuestos y no expuestos, se les comentó sobre el alcance, objetivo y secretividad de los resultados de la investigación, por lo cual aceptaron libremente participar de forma voluntaria firmando la hoja de consentimiento informado. Al final de la investigación se mostraron de manera confidencial los resultados a los pobladores expuestos y no expuestos de la comunidad. 


\section{RESULTADOS Y DISCUSIONES}

Para comenzar el trabajo de campo se diseñó el instrumento para la entrevista estructurada dirigida a pobladores expuestos y no expuestos al uso de plaguicidas, donde previamente se realizó una validación de la misma, aplicándola a personas dedicadas al rubro de la agricultura procedentes de la comunidad Argelia, Jamastrán, en el departamento de El Paraíso. Una vez listo el instrumento, se procedió a aplicar en la comunidad de La Brea, Lepaterique, efectuándose en tres días diferentes para cubrir el número de encuestados que se programó en el anteproyecto, de acuerdo al censo del Instituto Nacional de Estadística (INE), para un total de 73 pobladores expuestos y 69 no expuestos.

\section{Análisis de encuestas a pobladores no expuestos al uso de plaguicidas}

Del total de las 69 encuestas aplicadas, corresponden 12 a hombres y 57 a mujeres, de los cuales 53 afirmaron su interés por participar en el estudio y los restantes 16 negaron su interés, debido a diferentes motivos. Con respecto a las edades de las personas encuestadas, se observó que el mayor porcentaje oscilaba entre 20 y 29 años, con un total de quince entrevistados (ver gráfico 1).

\section{Gráfico 1. Edades de los pobladores no expuestas encuestados}

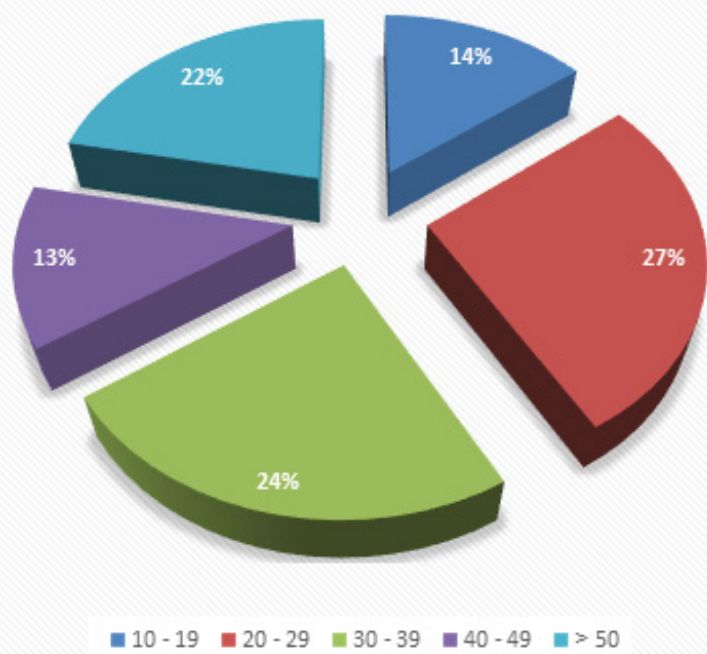

Fuente propia 
Con relación a la capacitación sobre el uso seguro y almacenamiento de plaguicidas, solamente un $14 \%$ señaló haber recibido algún curso o charla muy general sobre estos productos. Por otra parte, el instrumento reporto que un $35 \%$ de las personas encuestadas almacenan plaguicidas dentro de sus hogares, lo que representa un riesgo potencial a exposiciones accidentales con estos productos.

\section{Análisis de encuestas a pobladores expuestos al uso de plaguicidas}

En el caso de pobladores expuestos se entrevistaron un total de 73 personas, de las cuales 64 son del sexo masculino y 9 del sexo femenino; con la anuencia a participar en el estudio de 67 personas. En el gráfico 2 aparecen las edades de los pobladores que participaron, observándose entre las edades de 20 a 29 y 30 a 39, la mayor cantidad de pobladores que utilizan estos productos con un total de 40 individuos.

Cuando se analizan los datos obtenidos con relación a los años de utilizar plaguicidas, se encontró que la mitad de los entrevistados refirió utilizar plaguicidas desde hace diez años o más, con lo cual se denota que esta ha sido una práctica generalizada en la zona de estudio. Adicionalmente, un $14 \%$ y $12 \%$ ha empleado estos productos de 7 a 10 años y de 4 a 6 años, respectivamente.

\section{Gráfico 2. Edades de pobladores expuestos encuestados}

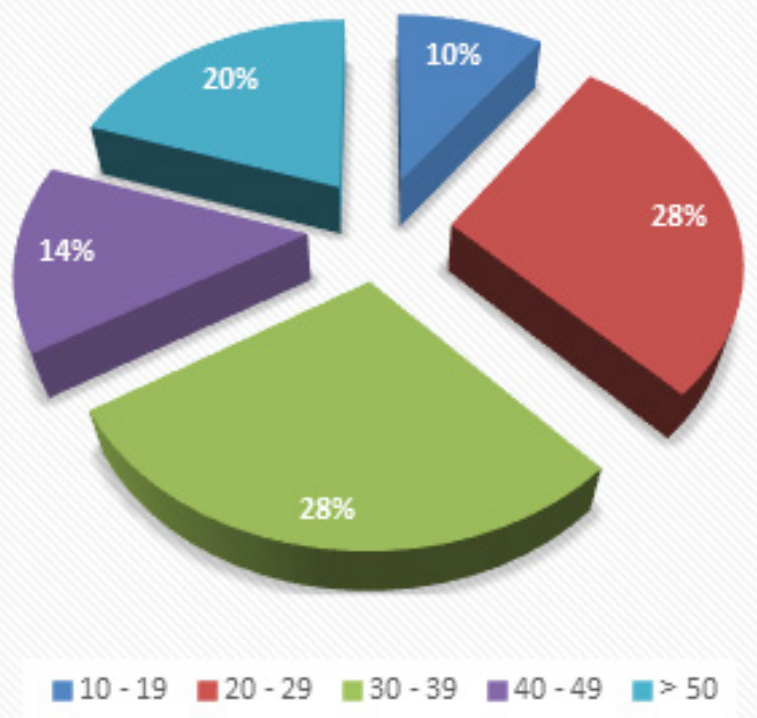

Fuente propia 
En la entrevista también se consultó la frecuencia semanal con que los pobladores utilizan estos productos, siendo el mayor porcentaje la de una a tres ocasiones por semana, esto significa que la exposición a los plaguicidas es elevada. Además, se consultó sobre el tiempo en horas que emplean para aplicar plaguicidas a los diferentes cultivos de hortalizas, en donde se encontró que un $62 \%$ de los entrevistados aplica los plaguicidas entre una y tres horas por cada aplicación, incrementando el riesgo a intoxicaciones accidentales. En cuanto a síntomas de exposición, un $42.5 \%$ de los encuestados afirmaron presentar algunas sintomatologías después de la aplicación de los plaguicidas, incluyendo cefalea, náuseas, mareos, debilidad muscular, irritación ocular y dérmica, entre otras.

La utilización de plaguicidas ha sido una práctica generalizada en la población de estudio. Al consultar a los encuestados sobre si han recibido algún curso sobre el manejo y uso seguro de plaguicidas, solamente un $33 \%$ señaló haberlo recibido, con lo cual se puede pensar que existe una gran necesidad de capacitación en la población de La Brea (ver gráfico 3).

\section{Grafico 3. Capacitación sobre uso y manejo seguro de plaguicidas}

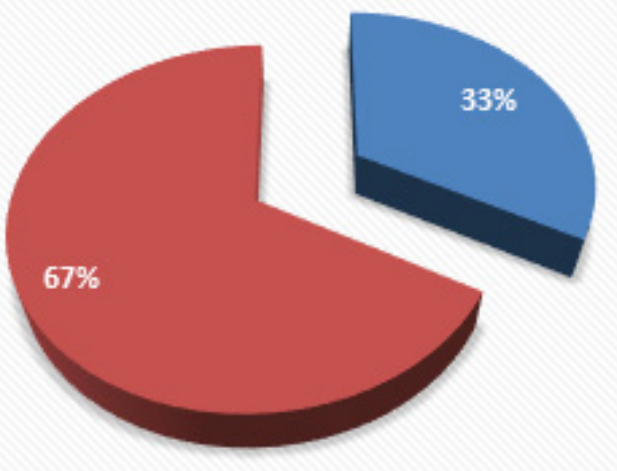

- $\mathrm{NI}$ NO

\section{Fuente propia}

Asimismo, ante la consulta sobre si ha leído la etiqueta presente en los frascos de los productos utilizados, un $79 \%$ de los encuestados, 58 personas, afirmaron haberlo hecho y un total de 52 personas mencionaron seguir las recomendaciones señaladas en la etiqueta, aunque comentaron hacerlo solamente para ver el modo de preparación del producto y no para ver las medidas de seguridad. Esta última consideración se denota cuando se le consultó a los pobladores expuestos sobre la utilización de 
protección personal al momento de aplicar los plaguicidas, a lo que el $75 \%$ de los entrevistados afirmó usar alguna protección, sin embargo, cuando se les solicitó mencionar que tipo de protección utilizaban, la gran mayoría refirió como protección para la aplicación de los productos, el uso de botas de hule y sombrero, no así para el uso de mascarilla, guantes, lentes y ropa de trabajo, con bajos porcentajes para la utilización de estas prendas, como se muestra en el gráfico 4.

\section{Gráfico 4. Protección personal para la aplicación de plaguicidas}

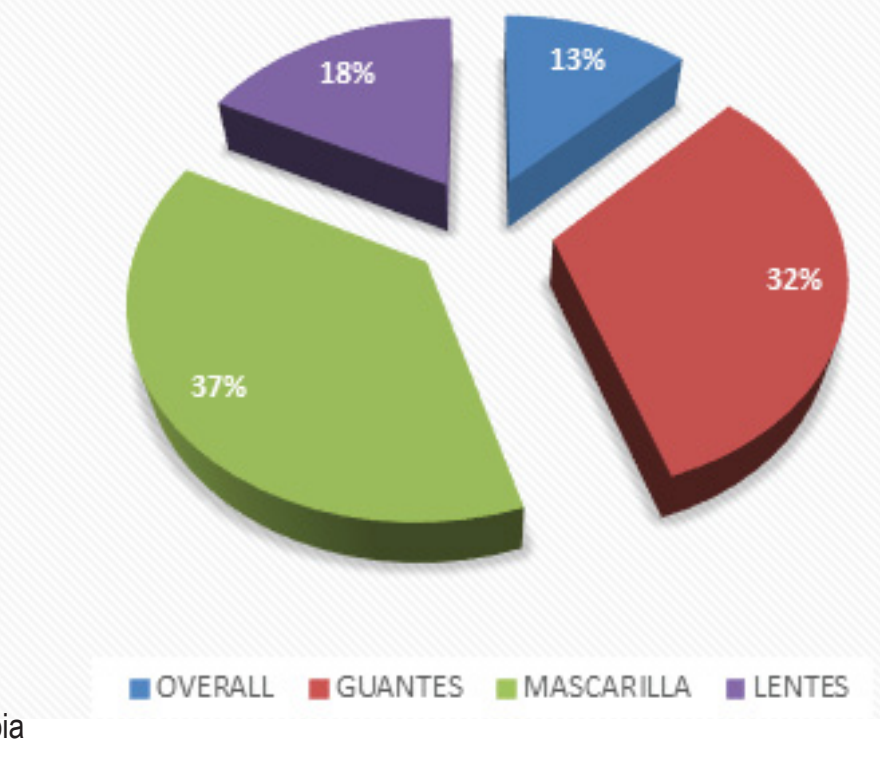

Fuente propia

Con respecto a los diferentes plaguicidas empleados por los pobladores expuestos la tabla 1, se muestran los más utilizados con su nombre comercial y algunas especificaciones relevantes, observándose la utilización de los de tipo organofosforados y carbamatos, principalmente.

\section{Determinación de la actividad de la enzima en sangre total}

Para evaluar la actividad de la enzima, se procedió a tomar las muestras de sangre venosa a los pobladores expuestos y no expuestos, empleando para ello tubos de plástico con anticoagulante. Previó a la toma de la muestra, se aplicó a cada uno de los voluntarios el consentimiento informado, en el cual se le explicaron los objetivos y alcances del estudio, así como el aseguramiento de que dichas muestras no serían empleadas para otros fines. Finalmente, cada uno de los voluntarios firmó el documento. 
Una vez recolectadas e identificadas con un código alfanumérico cada una de las muestras de sangre, las mismas fueron almacenadas a temperatura de refrigeración $\left(4^{\circ} \mathrm{C}\right)$, de modo que se siga la cadena de frío que asegure que la muestra conserva las características originales hasta el momento que sea ingresada al laboratorio. Este proceso fue llevado a cabo en tres visitas, para recolectar un total de 95 muestras, de las cuales 60 correspondieron a personas expuestas y las restantes 35 a personas no expuestas. Como puede verse, el número de personas no expuestas fue menor al que se consideró al momento de aplicar la encuesta, lo que se debió a la renuencia de las personas al método invasivo de toma de muestra, sin embargo, el número de muestras fue significativo para los objetivos del estudio.

Tabla 1. Plaguicidas utilizados por los pobladores y sus características principales

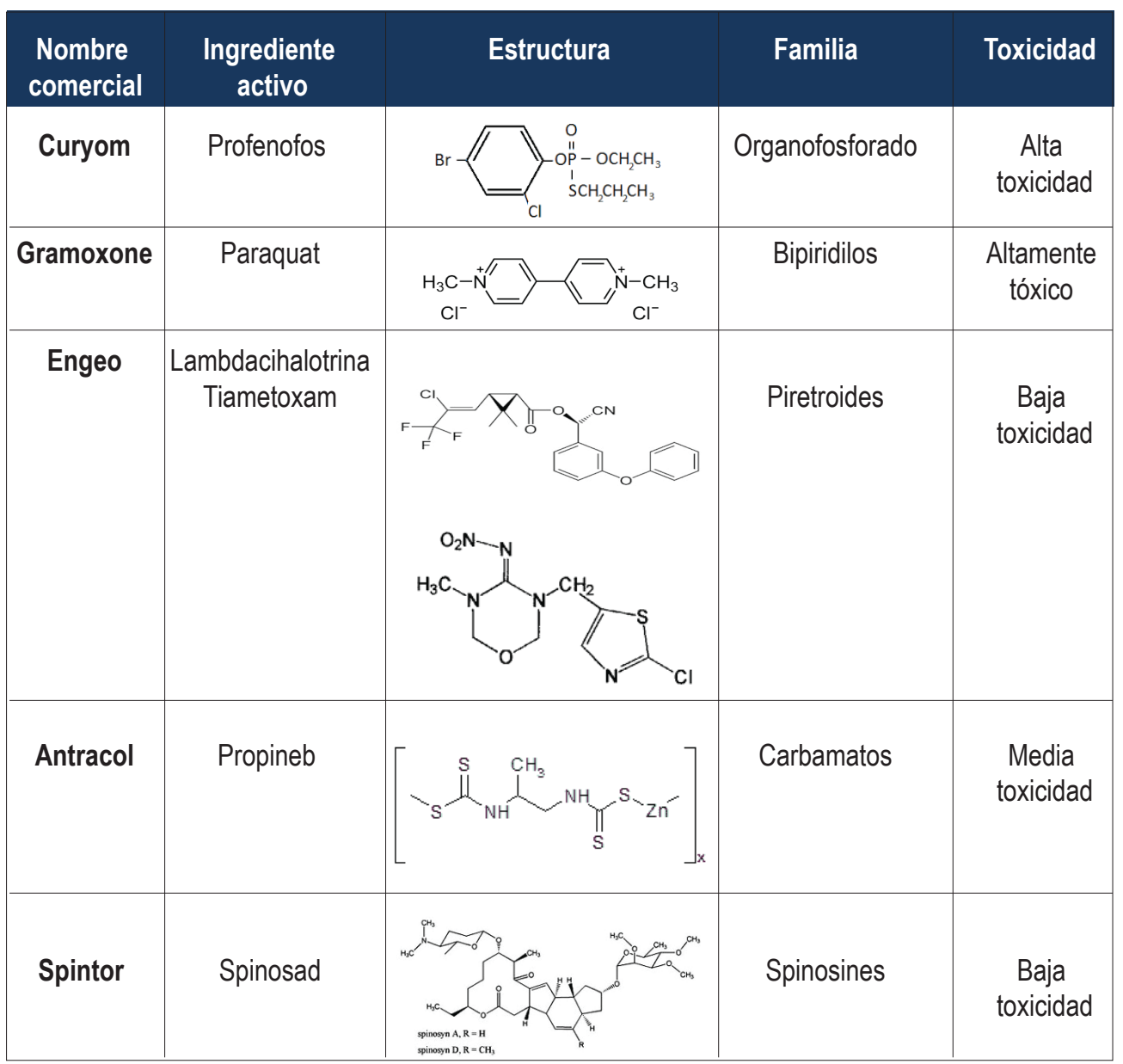

Fuente: Moffat, Osselton y Widdop, 2005. 


\section{Método potenciométrico de Michel}

El método consiste en una medición potenciométrica para obtener la cantidad de ácido por el cambio de pH producido por la acción de la enzima colinesterasa en un medio tamponado en tiempo determinado, aproximadamente una hora. La actividad enzimática se reporta en delta de unidades de pH/Hora (Carmona Fonseca, 2003). El procedimiento utilizado para la determinación se muestra en la figura 1, en donde la medición se realizó en un blanco de reactivos, control negativo, control positivo y las muestras recolectadas de pobladores expuestos y no expuestos de la comunidad en cuatro lotes de análisis. Cada una de las determinaciones se efectuó por triplicado, asegurando la confiabilidad de los resultados. Los resultados obtenidos de los cuatro lotes de análisis se presentan en la tabla 2, divididos por pobladores expuestos y no expuestos.

Tabla 2. Resultados de la actividad de la colinesterasa para pobladores expuestos y no expuestos

\begin{tabular}{|l|l|l|l|}
\hline \multicolumn{3}{|l}{ No expuestos } & No expuestos \\
\hline Código de identificación & Valor pH/hora & Código de identificación & Valor pH/hora \\
\hline 103 & 164.70 & 106 & 156.70 \\
\hline 202 & 165.00 & 108 & 148.70 \\
\hline 407 & 191.30 & 107 & 174.50 \\
\hline 406 & 145.00 & 208 & 140.70 \\
\hline 408 & 163.70 & 305 & 175.00 \\
\hline 104 & 165.00 & 705 & 160.00 \\
\hline 301 & 168.70 & 803 & 118.70 \\
\hline 303 & 177.00 & 704 & 132.00 \\
\hline 401 & 172.00 & 602 & 173.30 \\
\hline 207 & 186.70 & 706 & 172.30 \\
\hline 304 & 164.30 & 807 & 209.30 \\
\hline 302 & 182.00 & 701 & 201.30 \\
\hline 204 & 182.70 & 605 & 181.30 \\
\hline 402 & 156.00 & 806 & 172.70 \\
\hline 205 & 155.00 & 1 & 168.00 \\
\hline 403 & 170.70 & 6 & 143.00 \\
\hline 23 & 167.00 & 10 & 143.70 \\
\hline 25 & 176.00 & & \\
\cline { 1 - 2 } & & &
\end{tabular}




\begin{tabular}{|l|l|l|l|l|l|}
\hline \multicolumn{3}{|l|}{ Expuestos } & \multicolumn{2}{l|}{ Expuestos } & \multicolumn{2}{l|}{ Expuestos } \\
\hline $\begin{array}{l}\text { Código de } \\
\text { identificación }\end{array}$ & $\begin{array}{l}\text { Valor } \\
\text { pH/hora }\end{array}$ & $\begin{array}{l}\text { Código de } \\
\text { identificación }\end{array}$ & $\begin{array}{l}\text { Valor } \\
\text { pH/hora }\end{array}$ & $\begin{array}{l}\text { Código de } \\
\text { identificación }\end{array}$ & $\begin{array}{l}\text { Valor } \\
\text { pH/hora }\end{array}$ \\
\hline 105 & 180.70 & 9 & 173.00 & 606 & 188.70 \\
\hline 201 & 151.70 & 11 & 142.70 & 603 & 197.70 \\
\hline 102 & 157.00 & 12 & 159.70 & 907 & 192.70 \\
\hline 502 & 209.30 & 13 & 182.70 & 906 & 173.30 \\
\hline 203 & 156.30 & 14 & 186.70 & 905 & 206.00 \\
\hline 405 & 165.30 & 15 & 177.30 & 801 & 184.00 \\
\hline 206 & 163.70 & 16 & 168.70 & 802 & 201.00 \\
\hline 404 & 144.00 & 17 & 179.30 & 902 & 181.30 \\
\hline 503 & 184.30 & 18 & 188.30 & 808 & 185.70 \\
\hline 101 & 161.70 & 19 & 172.30 & 903 & 193.00 \\
\hline 501 & 163.30 & 20 & 177.70 & 2 & 131.30 \\
\hline 601 & 193.30 & 21 & 185.30 & 3 & 168.70 \\
\hline 904 & 154.00 & 22 & 204.30 & 4 & 125.50 \\
\hline 308 & 182.00 & 24 & 175.00 & 5 & 114.30 \\
\hline 307 & 178.70 & 26 & 168.70 & 7 & 182.70 \\
\hline 608 & 175.30 & 27 & 183.00 & 8 & 112.20 \\
\hline 604 & 179.00 & 28 & 169.70 & 901 & 173.00 \\
\hline 707 & 175.70 & 29 & 168.70 & 908 & 171.00 \\
\hline 708 & 186.70 & 30 & 176.70 & 805 & 185.70 \\
\hline 31 & 175.30 & 306 & 205.70 & 607 & 199.70 \\
\hline
\end{tabular}

\section{Fuente propia}

Una vez efectuadas las determinaciones potenciométricos se procedió a la tabulación y análisis de los datos obtenidos, encontrándose para los pobladores expuestos un valor promedio igual a $174.17 \mathrm{pH} / \mathrm{hora}$, con una desviación estándar de 20.51. Para el caso de los pobladores no expuestos, el promedio resultó ser igual a $166.40 \mathrm{pH} / \mathrm{ho}$ ra, con una desviación estándar de 18.54. Con estos datos se establecieron los valores de corte para estimar el nivel de exposición a los plaguicidas en ambos grupos de estudio, tomando como base la desviación estándar (ver tabla 3). 


\section{Tabla 3. Escala de actividad de la enzima colinesterasa en sangre total}

\begin{tabular}{|c|c|c|c|c|c|}
\hline Escala & Estado & $\begin{array}{l}\text { Obtención } \\
\text { estadística }\end{array}$ & $\begin{array}{l}\text { Límite } \\
\text { superior }\end{array}$ & $\begin{array}{l}\text { Límite } \\
\text { inferior }\end{array}$ & Descripción \\
\hline $\begin{array}{l}\text { Estado } \\
\text { normal }\end{array}$ & $\begin{array}{l}\text { Valor } \\
\text { normal }\end{array}$ & $\begin{array}{l}\text { Sin restar la } \\
\text { desviación } \\
\text { estándar }\end{array}$ & 174.17 & 154.00 & $\begin{array}{l}\text { Valores normales, personas } \\
\text { que no presentan ninguna } \\
\text { disminución en la actividad } \\
\text { enzimática. }\end{array}$ \\
\hline $\begin{array}{l}\text { Límite de } \\
\text { corte A }\end{array}$ & $\begin{array}{l}\text { Límite de } \\
\text { inhibición }\end{array}$ & $\begin{array}{l}\text { Menos una } \\
\text { desviación } \\
\text { estándar }\end{array}$ & 153.00 & 140.00 & $\begin{array}{l}\text { Personas que no presentan } \\
\text { inhibición, pero con actividad } \\
\text { enzimática baja por posibles } \\
\text { causas fisiológicas. }\end{array}$ \\
\hline $\begin{array}{l}\text { Límite de } \\
\text { corte B }\end{array}$ & $\begin{array}{l}\text { Leve } \\
\text { inhibición }\end{array}$ & $\begin{array}{l}\text { Menos dos } \\
\text { veces la } \\
\text { desviación } \\
\text { estándar }\end{array}$ & 139.00 & 133.00 & $\begin{array}{l}\text { Personas con una leve inhibic- } \\
\text { ión de la actividad enzimática } \\
\text { debido a exposición a } \\
\text { compuestos organofosforados } \\
\text { o carbamatos. }\end{array}$ \\
\hline $\begin{array}{l}\text { Límite de } \\
\text { corte C }\end{array}$ & $\begin{array}{l}\text { Moderada } \\
\text { inhibición }\end{array}$ & $\begin{array}{l}\text { Menos tres } \\
\text { veces la } \\
\text { desviación } \\
\text { estándar }\end{array}$ & 129.00 & 113.00 & $\begin{array}{l}\text { Personas con una moderada } \\
\text { inhibición, propensas a riego } \\
\text { de intoxicación con plaguicidas } \\
\text { organofosforados o carbama- } \\
\text { tos. }\end{array}$ \\
\hline
\end{tabular}

Fuente propia

Con base a esta escala, se encontró que el mayor porcentaje de evaluados presentó valores de $\mathrm{pH} /$ hora normales y solamente tres pobladores expuestos y cinco pobladores no expuestos presentaron valores en el límite de inhibición, pudiendo considerarse adecuadas. Solamente dos pobladores, uno por cada grupo de estudio, mostraron valores para una leve inhibición. Finalmente, tres pobladores expuestos con inhibición moderada, mostrando valores iguales a 112, 114 y 125 unidades de pH/hora. Cabe mencionar que los resultados obtenidos reflejan que el valor promedio de la actividad de la colinesterasa en sangre para los pobladores de La Brea, Lepaterique, es mucho más elevado que los que se reportan en la literatura para poblaciones latinoamericanas. 


\section{CONCLUSIONES}

En el presente trabajo, al referirnos a los pobladores no expuestos encuestados, se encontró que la mayoría es del género femenino, entre 20-29 años, desempeñándose como amas de casa. Asimismo, dentro de la población encuestada se determinó que un $14 \%$ ha recibido charlas de capacitación sobre el manejo de plaguicidas y un $35 \%$ de toda la población encuestada almacena estos productos en casa, lo que incrementa el riesgo a intoxicaciones por plaguicidas, pudiendo verse afectados los niños y ancianos.

En cuanto a los pobladores expuestos encuestados se determinó, como podría preverse, que la mayoría es del género masculino en una edad comprendida entre 20 a 40 años, siendo la fuerza productiva de la comunidad de La Brea, Lepaterique, que se dedican principalmente a dicha actividad. Cabe señalar que el $50 \%$ de los entrevistados poseen más de 10 años de trabajar con plaguicidas y el $62 \%$ afirmó que lo realizan con una frecuencia de 1 a 3 veces por semana; con lo que este grupo se encuentra con mayor riesgo de intoxicaciones agudas y crónicas por el uso de plaguicidas.

Aunque el $33 \%$ de la población asegura haber recibido charlas sobre el uso y manejo seguro de los plaguicidas, se manifiesta que existe una contradicción debido a que no aplican las medidas de seguridad, tales como el uso de indumentaria adecuada, refiriéndose a esta no solo el uso de botas y sombrero, como lo afirmaban los encuestados. Pese a que un porcentaje menor señaló que utilizaba las medidas de protección como mascarilla, guantes y gafas, se observó que no cumplen con dichas medidas. Con base a lo anterior, se puede concluir que es prioritario realizar capacitaciones sobre la temática y 0 , concientizar a la población sobre los riesgos a lo que están expuestos.

Al no utilizar una protección adecuada para la aplicación de los productos, la población se ve afectada al momento de la aplicación, encontrándose el reporte de síntomas como cefaleas, náuseas, mareos, debilidad muscular, irritación muscular y dérmica. Esto incide en la salud de los trabajadores, por una parte, con afecciones inmediatas; pero, además, a largo plazo, se denota visualmente un envejecimiento prematuro en las personas, lo que también se ve influenciado por hábitos alimenticios y condiciones de vida.

Cabe mencionar que los plaguicidas organofosforados y carbamatos pueden inhibir 
la enzima colinesterasa y se encontró que en el listado de productos más utilizados en el combate de las plagas se encuentran el Curyom, perteneciente a la familia de los organofosforados, Antracol (carbamatos) y otros también de uso común como el Gramoxone, Engeo y Spintor.

De acuerdo con los resultados obtenidos en el análisis para la determinación de los valores normales de la enzima colinesterasa en sangre en los pobladores expuestos y no expuestos, se considera normal un valor de mayor o igual a $154 \mathrm{pH} / \mathrm{hora}$. El estudio demostró que un bajo porcentaje de pobladores expuestos obtuvieron valores de leve inhibición e inhibición moderada, lo que no excluye la posibilidad de intoxicación por el uso de plaguicidas. Finalmente, los valores fueron presentados a la población, enfocándose en el diseño del plan de manejo y normas de seguridad para la utilización de plaguicidas, lo mismo que el tratamiento de los desechos de estos productos.

\section{AGRADECIMIENTO}

A la Dirección de Investigación Científica y Posgrados de la UNAH por otorgar la beca básica de investigación para hacer posible este estudio y la adquisición del equipamiento de laboratorio necesario De igual manera, al Decanato de la Facultad de Química y Farmacia por el apoyo ofrecido durante la investigación, incluyendo la adquisición del equipo multiparamétrico, el cual no dudamos podrá ser utilizado en futuras investigaciones; a la jefatura del Departamento de Control Químico, por la apertura y respaldo al trabajo de los investigadores involucrados en el proyecto. Nuestro sincero agradecimiento por su colaboración a los miembros de la comunidad de La Brea, especialmente al presidente del patronato, Miguel Martínez y el vicealcalde del municipio de Lepaterique, Santos Sierra, quienes fueron el enlace entre la comunidad y los investigadores. 


\section{BIBLIOGRAFÍA}

Carmona-Fonseca, J. (2003). Valores de referencia de la actividad de la colinesterasa eritrocitaria según las técnicas de Michel y EQM(R) en población laboral de antioquia, Colombia. Rev. Panam Salud Publica, 316-324.

Cobb, H.A., Reade, J.P.H. (2010). Herbicide Discovery and Development. En H. R. Cobb, Herbicides and Plant Physiology (págs. 27-49). Wiley and Soons.

Cotos, M., Manuel, O., Horna, P., \& William, R. (2002). Niveles de colinesterasa sérica en aqricultores de la localidad de Carapongo (perú) y determinación de residuos de plaguicidas inhibidores de la Acetilcolinesterasa en frutas y hortalizas cultivadas. Tesis previo al titulo de licenciado químico-farmacéutico. Lima, Perú: Universidad Nacional Mayor de San Marcos.

Fong Flores, O., Barreiro Domench, I., Rodríguez, J., Marin Sanchez, D., Wawoe Díaz, M., \& Colon Suárez, M. (2010). Método potenciometrico de Michel modificado para la determinación de la actividad colinesterasa. Revista Cubana de Química, 45-52.

Moffat, A.C.; Osselton, M.D.; Widdop, B. (2005). Clarke's Analysis of Drugs and Poisons. Londrés: Pharmaceutical Press.

Systems, C. R. (27 de Marzo de 2016). Creative Research Systems. Obtenido de Creative Research Systems: www.surveysystem.com/sscalc.htm 